\title{
Classe dirigente e cultura política no estado do Paraná (2002-2006)
}

\section{Resumo}

O objetivo deste trabalho é identificar a visão de democracia dos membros de três frações da classe dirigente paranaense: a elite político-

Renato Perissinotto'

Paula Adriana Wagnitz²

administrativa, a elite parlamentar e a elite judiciária. Para tanto, comparam-se os dados obtidos pelas pesquisas "Quem são e o que pensam os desembargadores do Tribunal de Justiça do estado do Paraná: 2005-2006" e "Quem Governa? Mapeando as elites políticas e econômicas no Paraná contemporâneo" (2002-2006), ambas realizadas pelo Núcleo de Pesquisa em Sociologia Política Brasileira da Universidade Federal do Paraná. Foram entrevistados 71 desembargadores, 48 parlamentares e 22 secretários de Estado. Conclui-se que, apesar de uma adesão praticamente universal à democracia, as três frações da classe dirigente têm diferenças significativas quanto ao tipo de democracia que defendem, diferenças essas que podem ser hipoteticamente atribuídas ao tipo de recrutamento e ao processo de socialização política e profissional a que seus membros são submetidos.

Palavras-chave: classe dirigente, cultura política, democracia, Paraná.

1 Professor do Programa de Pós-Graduação em Ciência Política da Universidade Federal do Paraná, co-editor da Revista de Sociologia e Política e co-coordenador do Núcleo de Pesquisa em Sociologia Política. Atualmente encontra-se em estágio de pós-doutorado no Latin American Centre, University of Oxford, com bolsa do CNPq. Endereço eletrônico: <monseff@uol.com.br>

2 Graduanda em Ciências Sociais na Universidade Federal do Paraná, pesquisadora e co-coordenadora do Núcleo de Pesquisa em Sociologia Política Brasileira na mesma Universidade. Durante a pesquisa que deu origem a este artigo, foi bolsista de iniciação científica do CNPq. Endereço eletrônico: <paula.wagnitz@gmail.com> 


\section{Apresentação}

Estudos sobre cultura política sugerem com frequência que os valores políticos dos membros dos grupos dirigentes, especialmente daqueles que se constituem em operadores diretos do sistema político, são fundamentais para o bom (ou mal) funcionamento e para a estabilidade (ou instabilidade) dos regimes democráticos (ALMOND; VERBA, 1989; VERBA, 1980; PUTNAM, 1971, 1976 E 1996; DAHL, 1989 e 2005). Este artigo tem dois objetivos principais. Primeiro, pretendemos descrever os valores políticos das diferentes frações da classe dirigente paranaense, nos anos de 2002 a 2006; segundo, pretendemos analisar esses valores em função das diversas formas de recrutamento por que passam os membros das diferentes frações da classe dirigente. Como observou Moshe Czudnowsky, "os critérios normativos para a mudança ou manutenção do status quo são articulados pelas elites políticas e é por meio do processo de recrutamento que elites potenciais portadoras de um ou outro conjunto de critérios normativos serão selecionadas para o exercício de papéis decisórios" (1975, p. 158). Essa relação entre processo de recrutamento e valores políticos é o fio condutor do presente trabalho ${ }^{3}$. Antes, porém, de abordarmos diretamente os dados, três observações de natureza teórica e metodológica são importantes.

Primeiramente, o termo "classe dirigente" engloba, neste texto, três frações importantes dos grupos dirigentes do Estado: os deputados estaduais (elite parlamentar), governador e secretários de Estado (elite político-administrativa) e os desembargadores do Tribunal de Justiça do Paraná (elite judiciária). Os membros de todas essas frações concentram em suas mãos o poder de tomar

3 Como observa o próprio Czudnovsky, a relação entre processo de recrutamento das elites políticas e seus valores já fora abordada antes por Almond, no seu "A functional approach to comparative politics", de 1960. Ver também o excelente trabalho de Kenneth Prewitt. Para esse autor, um dos resultados mais importantes do processo de recrutamento é a seleção de indivíduos portadores de valores e percepções compatíveis com o status quo político. Cf. Prewwitt, 1970, p. 111-127. 
decisões que afetam a vida de milhões de pessoas no estado. Como se percebe, o termo classe dirigente, tal como utilizado aqui, vai além daquilo que normalmente se considera a "elite política", isto é, os ocupantes de cargos que, de alguma forma, passam pelo crivo eleitoral ${ }^{4}$.

Em segundo lugar, os dados foram coletados a partir de duas pesquisas diferentes, ainda que orientadas por questões similares. Os dados referentes aos desembargadores foram coletados durante a pesquisa "Quem são, o que pensam e como julgam os Desembargadores do Paraná?", realizada em 2006 pelo Núcleo de Pesquisa em Sociologia Política Brasileira da Universidade Federal do Paraná. De um universo de 120 desembargadores, 71 foram entrevistados. O questionário foi composto por cerca de 120 questões distribuídas por sete blocos: i) informações pessoais, ii) origem social, iii) trajetória escolar, iv) carreira profissional, v) valores jurídicos, políticos e sociais, vi) atividade acadêmica e intelectual e, por fim, vii) dados relativos à participação e associativismo (CASTRO et al., 2009).

Os dados referentes à elite parlamentar e à elite político-administrativa são oriundos da pesquisa "Quem Governa? Mapeando as elites políticas e econômicas no Paraná contemporâneo" realizada entre os períodos de 2002 a 2006, pelo mesmo Núcleo, durante o primeiro mandato do governador Roberto Requião (os

4 Duas críticas são normalmente feitas ao conceito de "classe dirigente" tal como formulado pelos autores elitistas clássicos, a saber, que ele pressupõe, primeiro, a homogeneidade e coesão do grupo e, segundo, a "naturalização" das posições de poder. Na verdade, a tese de que o conceito de "classe dirigente" pressupõe "homogeneidade" é válida, quando muito, apenas para os escritos de juventude de Gaetano Mosca, como sugere James H. Meisel (1962, capítulo 9). Ettori Albertoni (1990, p. 75), porém, defende que nem mesmo nas obras de juventude encontramos uma visão monolítica da classe dirigente. Posteriormente, na segunda edição de The Ruling Class, Mosca descreve a classe política dos governos representativos como institucionalmente fragmentada e socialmente heterogênea. Acreditamos que, para esse autor, questões sobre a coesão ou fragmentação da classe política (ou classe dirigente) só podem ser respondidas pela pesquisa empírica. No que diz respeito à suposta naturalização das posições de poder inerente às proposições elitistas, isso talvez seja verdade para Pareto, mas certamente não o é para Gaetano Mosca. A tipologia mosquiana das classes dirigentes existentes ao longo da história revela o caráter necessariamente histórico e sociológico deste conceito. Quanto a esse ponto, cf. Mosca, 1939, capítulo II. 
dados referentes ao segundo mandato estão ainda em processo de coleta). Seu objetivo consistiu em traçar o perfil de três elites paranaenses distintas - os parlamentares (deputados da Assembleia Legislativa do Paraná), os secretários (que são nomeados pelo governador), e os líderes partidários. As 50 questões que compõem o questionário foram distribuídas entre três blocos: i) carreira política, ii) valores políticos e iii) informações pessoais e familiares. Foram entrevistados 48 deputados (de 54 cargos, sem contar a entrada de suplentes), 22 secretários (de 34 postos, contando com o governador, vice-governador, secretários de estado, comandantes das polícias e diretores de algumas empresas estatais), 9 líderes partidários (distribuídos entre PDT, PFL, PMDB, PP, PSDB, PT e PTB) e 5 pessoas que integravam mais de uma elite. Na presente análise trabalhamos apenas com os membros da elite parlamentar e do setor político-administrativo, excluindo o setor partidário (CODATO et al., 2010).

$\mathrm{O}$ artigo está estruturado da seguinte maneira. Na primeira parte, discutimos a adesão das diferentes frações da classe dirigente ao regime democrático; na segunda parte, analisamos o tipo de democracia a que essas frações aderem, se a uma democracia mais ou menos participativa, mais ou menos substantiva; em seguida, investigamos quais são, para esses membros da classe dirigente, os principais obstáculos à consolidação da democracia no Brasil. Por fim, à guisa de conclusão, procuramos interpretar as diferenças detectadas pela pesquisa entre as três frações da classe dirigente paranaense a partir dos diferentes processos de recrutamento e de socialização política a que estão submetidos seus membros.

\section{Classe dirigente e adesão à democracia}

Quando instados a responder qual seria a melhor forma de governo, 86,4\% (19 entre 22) dos secretários, 89,6\% (43 entre 48) dos parlamentares e 98,6\% (69 entre 70) dos magistrados entrevistados responderam que um governo democrático é sempre a melhor forma de governo. Desse ponto de vista, portanto, não 
há muito a discutir. A esmagadora maioria dos membros das três frações da classe dirigente paranaense revela aderir ao regime democrático como melhor forma de governo, parecendo rejeitar a ditadura como alternativa desejável. ${ }^{5}$

No entanto, essa adesão massiva e genérica ao regime democrático deve ser testada por outras questões. No nosso caso, submetemos os entrevistados a um conjunto de situações hipotéticas em que o acirramento de determinados conflitos pudesse colocar em perigo alguns valores supostamente caros ao grupo. Perguntamos, então, se aceitariam suspender o regime democrático nesses casos específicos. Os resultados podem ser vistos no quadro 1 a seguir.

Quadro 1 - Situações em que aceita o fim do Regime Democrático ${ }^{6}$

\begin{tabular}{|c|c|c|}
\hline & Concorda & Discorda \\
\hline $\begin{array}{l}\text { Quando houver ameaça generalizada ao } \\
\text { direito de propriedade privada }\end{array}$ & $\begin{array}{l}\text { P: } 41,7 \%(20) \\
\text { A: } 13,6 \%(3) \\
\text { J: } 16,9 \%(12)\end{array}$ & $\begin{array}{l}\text { P: } 58,3 \%(28) \\
\text { A: } 86,4 \%(19) \\
\text { J: } 83,1 \%(59)\end{array}$ \\
\hline $\begin{array}{l}\text { Quando houver ameaça generalizada } \\
\text { aos valores morais e religiosos de nossa } \\
\text { sociedade }\end{array}$ & $\begin{array}{l}\text { P: } 39,6 \%(19) \\
\text { A: } 13,6 \%(3) \\
\text { J: } 26,8 \%(19)\end{array}$ & $\begin{array}{l}\text { P: } 58,3 \%(28) \\
\text { A: } 86,4 \%(19) \\
\text { J: } 73,2 \%(52)\end{array}$ \\
\hline $\begin{array}{l}\text { Quando houver ameaça à ordem pública } \\
\text { em função de crise econômica aguda }\end{array}$ & $\begin{array}{l}\text { P: } 35,4 \%(17) \\
\text { A: } 13,6 \%(3) \\
\text { J: } 21,1 \%(15)\end{array}$ & $\begin{array}{l}\text { P: } \quad 62,5 \%(30) \\
\text { A: } 86,4 \%(19) \\
\text { J: } 78,9 \%(56)\end{array}$ \\
\hline Quando houver descontrole da corrupção & $\begin{array}{l}\text { P: } 39,6 \%(19) \\
\text { A: } 13,6 \%(3) \\
\text { J: } 15,7 \%(11)\end{array}$ & $\begin{array}{l}\text { P: } 58,3 \%(28) \\
\text { A: } 86,4 \%(19) \\
\text { J: } 84,3 \%(59)\end{array}$ \\
\hline $\begin{array}{l}\text { Quando houver ameaça ao Estado pelo } \\
\text { crime organizado }\end{array}$ & $\begin{array}{l}\text { P: } 41,7 \%(20) \\
\text { A: } 18,2 \%(4) \\
\text { J: } 25,7 \%(18)\end{array}$ & $\begin{array}{l}\text { P: } 58,3 \%(28) \\
\text { A: } 81,8 \%(18) \\
\text { J: } 74,3 \%(52)\end{array}$ \\
\hline
\end{tabular}

(Continua)

5 "Com qual das seguintes frases o(a) sr.(a) concorda? Por favor, escolha apenas uma: 1) a democracia é sempre a melhor forma de governo; 2) a democracia às vezes é a melhor forma de governo; 3) a democracia nunca é a melhor forma de governo; 4) é indiferente ter ou não uma democracia."

6 Em todos os quadros de dados não foram computadas as pessoas que não quiseram responder às perguntas, mas apenas o total das que efetivamente responderam. Apenas um parlamentar não respondeu a cinco das sete alternativas apresentadas e somente um desembargador se recusou a opinar sobre duas delas. 
Classe dirigente e cultura política no estado do Paraná (2002-2006)

Renato Perissinotto • Paula Adriana Wagnitz

\begin{tabular}{|l|l|l|}
\hline & \multicolumn{1}{|c|}{ Concorda } & \multicolumn{1}{|c|}{ Discorda } \\
\hline Quando houver ameaça generalizada de & P: $16,7 \%(8)$ & P: $81,3 \%(39)$ \\
quebra da hierarquia nas instituições & A: $18,2 \%(4)$ & A: $81,8 \%(18)$ \\
militares & J: $18,3 \%(13)$ & J: $81,7 \%(58)$ \\
\hline \multirow{2}{*}{ O fim do regime democrático não é } & P: $54,2 \%(26)$ & P: $43,8 \%(21)$ \\
aceitável em hipótese alguma & A: $86,4 \%(19)$ & A: $13,6 \%(3)$ \\
& J: $64,8 \%(46)$ & J: $35,2 \%(25)$ \\
\hline
\end{tabular}

Fonte: Núcleo de Pesquisa em Sociologia Política Brasileira (NUSP)

P: elite parlamentar

A: elite político-administrativa

J: elite judiciária

Os resultados são bastante interessantes, tanto no que se refere ao fato de que a adesão generalizada detectada anteriormente cede lugar a posições bem mais cautelosas, quanto pelas diferenças identificadas entre as três frações da classe dirigente.

Das três elites, a fração parlamentar da classe dirigente é a que mais aceita o término da democracia diante das situações hipotéticas colocadas, sobretudo no caso de ameaça à propriedade privada e ao Estado pelo crime organizado. Essa fração é também a que expressa mais discordância quanto à ideia de que o fim do regime "não é aceitável em hipótese alguma" $(43,8 \%$, contra 13,6\% da fração político-administrativa e $35,2 \%$ da fração judiciária) ${ }^{7}$. Esse achado é particularmente curioso, pois era de se esperar que o contrário ocorresse, já que a própria existência da elite parlamentar depende diretamente do funcionamento de um sistema baseado na competição eleitoral.

Esse dado sugere, ao menos para esse caso, que a simples participação ativa e direta do procedimento-chave de recrutamento da democracia representativa, a competição eleitoral, não seria suficiente para produzir efeitos de socialização política que favorecessem a

7 É interessante observar que o cruzamento entre o setor do entrevistado (Parlamentar, Administrativo, Judiciário) e as questões acima só foram significativos para as alternativas "quando houver ameaça generalizada ao direito de propriedade" e "quando houver descontrole da corrupção". A análise dos resíduos padronizados mostra que as relações significativas se concentram exatamente nos parlamentares. 
adesão a essa forma de governo. Reforçando essa proposição, não encontramos qualquer tipo de associação significativa entre o tempo de carreira dos parlamentares e suas posições sobre a suspensão ou não do regime democrático, o que também é curioso, pois, de acordo com as teorias sobre socialização política, o tempo de exposição a determinados procedimentos é fundamental para a inculcação de valores e crenças, desde que, é claro, os processos de socialização sejam adequadamente institucionalizados e funcionem satisfatoriamente. Assim, estaríamos diante de duas possibilidades, ou, de um lado, os espaços de socialização política inerentes à vida eleitoral (em especial os partidos políticos) não operam satisfatoriamente ou, de outro lado, o que se aprende ali pouco tem a ver com os valores antecipados pela nossa pesquisa.

Nas outras duas frações da classe dirigente percebemos uma rejeição bem maior às proposições referentes ao fim da democracia, especialmente no âmbito da elite político-administrativa (os secretários de Estado). Com relação a essa fração, impressiona a regularidade de seus percentuais. Em quase todas as questões, $86,4 \%$ de seus membros dão respostas favoráveis à permanência do sistema democrático. No caso da fração judiciária, também a grande maioria de seus membros dão respostas condizentes com a adesão à democracia, embora nesse caso não deixe de surpreender que $35,2 \%$ dos autointitulados defensores do Estado de Direito se declarem contra a proposição de que o fim do regime democrático não é aceitável em hipótese alguma.

Como explicar essa situação em que a fração da classe dirigente recrutada pelo procedimento democrático típico - a competição eleitoral - seja mais propensa a aceitar o fim da democracia do que frações cuja forma de recrutamento é predominantemente autocrática (no caso dos membros do secretariado) ou burocrática (no caso dos desembargadores)? É difícil responder com segurança a essas questões a partir dos nossos dados. Podemos especular, porém, que tais diferenças de adesão tenham mais a ver com o perfil ideológico dos entrevistados do que propriamente com o modo pelo qual são 
recrutados para as suas funções ${ }^{8}$. Com relação a esse ponto, vale ressaltar que a correlação entre a posição ideológica dos entrevistados (nesse caso, apenas parlamentares e secretários de Estado) e suas opiniões sobre as situações hipotéticas que justificariam o fim da democracia foram significativas em todos os cruzamentos, como se pode atestar pela quadro abaixo':

Quadro 2 - Coeficiente de contingência entre posição ideológica e defesa do fim da democracia

\begin{tabular}{|l|c|c|}
\hline & CC & Sig. \\
\hline $\begin{array}{l}\text { O fim do regime democrático é aceitável quando houver } \\
\text { ameaça generalizada ao direito de propriedade privada }\end{array}$ & 0,53 & 0,000 \\
\hline $\begin{array}{l}\text { O fim do regime democrático é aceitável quando houver } \\
\text { ameaça generalizada aos valores morais e religiosos de } \\
\text { nossa sociedade }\end{array}$ & 0,48 & 0,021 \\
\hline $\begin{array}{l}\text { O fim do regime democrático é aceitável quando houver } \\
\text { ameaça à ordem pública em função de crise econômica } \\
\text { aguda }\end{array}$ & 0,53 & 0,002 \\
\hline $\begin{array}{l}\text { O fim do regime democrático é aceitável quando houver } \\
\text { descontrole da corrupção }\end{array}$ & 0,57 & 0,000 \\
\hline $\begin{array}{l}\text { O fim do regime democrático é aceitável quando houver } \\
\text { ameaça ao Estado pelo crime organizado }\end{array}$ & 0,44 & 0,004 \\
\hline $\begin{array}{l}\text { O fim do regime democrático é aceitável quando houver } \\
\text { ameaça generalizada de quebra da hierarquia nas } \\
\text { instituições militares }\end{array}$ & 0,51 & 0,006 \\
\hline $\begin{array}{l}\text { O fim do regime democrático não é aceitável em hipótese } \\
\text { alguma }\end{array}$ & 0,47 & 0,029 \\
\hline
\end{tabular}

8 Em determinado momento da entrevista, os secretários e deputados deveriam se autoposicionar em uma escala ideológica de 1 a 7 , sendo que o número 1 indicava a posição mais à esquerda e o 7 , a posição mais à direita. Infelizmente, a mesma pergunta não foi feita para os desembargadores, o que impede a comparação quanto a este ponto.

9 Essa mesma relação entre posição ideológica e apego à democracia foi analisada para os parlamentares do período de 1995-2002, durante o governo de Jaime Lerner, constatando-se que quanto mais à esquerda, maior a adesão dos deputados ao regime democrático. Ver Perissinotto e Braunert, 2006. 
Quando analisamos os setores parlamentar e político-administrativo separadamente, os resultados do cruzamento entre posição ideológica e defesa do fim da democracia são mais significativos para os parlamentares porque entre eles a divisão entre esquerda e direita é mais acentuada, sendo mais fácil testar a associação entre as duas variáveis. Entre os entrevistados desse grupo, $48 \%$ se identificaram como sendo de esquerda, $27,1 \%$ como de centro e $20,9 \%$ como de direita. Entre os membros do setor político-administrativo, os percentuais são $72,7 \%, 22,7 \%$ e $4,5 \%$, respectivamente ${ }^{10}$. Nesse sentido, os valores em questão talvez tenham a ver mais com a socialização política de parlamentares do que com sua seleção pelo procedimento eleitoral. É verdade que a competição eleitoral é apenas um momento do processo de seleção dos deputados estaduais e que os procedimentos anteriores, notadamente a formação das listas de candidatos dentro dos partidos, são pouco democráticos, mas o interesse em manter o regime político ao menos por razões de autopreservação deveria contribuir para atenuar posições mais tolerantes quanto ao fim da democracia, o que, como vimos, não é o caso.

\section{Qual democracia?}

É preciso avançar um pouco mais nessa questão acerca da adesão ao regime democrático. Cabe perguntar se é possível encontrar entre as diferentes frações da classe dirigente paranaense algum tipo de resposta mais frequente quanto ao tipo de democracia que eles têm em mente. Teriam eles uma compreensão mais procedimental, à la Schumpeter (1961), ou mais partici-

10 As tabelas de contingência que deram origem aos coeficientes acima revelam uma clara propensão para os indivíduos situados à esquerda optarem pela defesa da manutenção do sistema democrático, diferentemente dos que se situam à direita do espectro ideológico (ao menos, é claro, no que diz respeito às questões por nós formuladas). Para os parlamentares isoladamente, os resultados foram significativos para a defesa do fim da democracia em caso de corrupção ( $\operatorname{sig}=0,008$ e coeficiente de contingência de 0,57 ); em caso de quebra da hierarquia militar ( $\mathrm{sig}=0,0046$ e coeficiente de contingência de 0,52 ) e, por fim, em caso de ameaças à propriedade privada ( $\operatorname{sig}=0,000$ e coeficiente de contingência de 0,50 ). 
pativa, à la Pateman (1992), do regime democrático? Democracia seria um sistema baseado essencialmente na igualdade política, como a poliarquia dahlsiana (2005), ou deveria também contemplar algum nível de igualitarismo social, como no caso da tradição marxista? Comecemos pela primeira questão.

A fim de saber se os entrevistados tinham uma visão de democracia mais ou menos participativa pensamos um conjunto de questões que procuravam contemplar tanto o procedimento fundamental da democracia representativa - o voto - como formas alternativas de participação. Os dados podem ser vistos no quadro 3 a seguir.

Quadro 3 - Democracia e participação ${ }^{11}$

\begin{tabular}{|c|c|c|c|}
\hline & Concorda & $\begin{array}{c}\text { Nem } \\
\text { concorda } \\
\text { nem discorda }\end{array}$ & Discorda \\
\hline $\begin{array}{l}\text { Só há democracia se } \\
\text { houver a participação do } \\
\text { cidadão pelo voto }\end{array}$ & $\begin{array}{l}\text { P: } 93,8 \%(45) \\
\text { A: } 95,5 \%(21) \\
\text { J: } 91,5 \%(65) \\
\end{array}$ & $\begin{array}{l}\text { P: } 4,2 \%(2) \\
\text { A: } 4,5 \%(1) \\
\text { J: } 4,2 \%(3)\end{array}$ & $\begin{array}{l}\text { P: } 2,1 \%(1) \\
\text { A: } 0 \\
\text { J: } 4,2 \%(3)\end{array}$ \\
\hline $\begin{array}{l}\text { Só há democracia se } \\
\text { houver participação do } \\
\text { cidadão por meio de } \\
\text { plebiscitos realizados } \\
\text { regularmente }\end{array}$ & $\begin{array}{l}\text { P: } 60,4 \%(29) \\
\text { A: } 18,2 \%(4) \\
\text { J: } 34,3 \%(24)\end{array}$ & $\begin{array}{l}\text { P: } 16,7 \%(8) \\
\text { A: } 40,9 \%(9) \\
\text { J: } 20,0 \%(14)\end{array}$ & $\begin{array}{l}\text { P: } 22,9 \%(11) \\
\text { A: } 40,9 \%(9) \\
\text { J: } 45,7 \%(32)\end{array}$ \\
\hline $\begin{array}{l}\text { Só há democracia se } \\
\text { houver a participação do } \\
\text { cidadão por meio dos } \\
\text { conselhos gestores de } \\
\text { políticas públicas }\end{array}$ & $\begin{array}{l}\text { P: } 68,8 \%(33) \\
\text { A: } 54,5 \%(12) \\
\text { J: } 36,2 \%(25)\end{array}$ & $\begin{array}{l}\text { P: } 12,5 \%(6) \\
\text { A: } 13,6 \%(3) \\
\text { J: } 20,3 \%(14)\end{array}$ & $\begin{array}{l}\text { P: } 19,7 \%(8) \\
\text { A: } 31,8 \%(7) \\
\text { J: } 43,5 \%(30)\end{array}$ \\
\hline $\begin{array}{l}\text { Só há democracia se } \\
\text { houver a participação } \\
\text { do cidadão por meio de } \\
\text { orçamento participativo }\end{array}$ & $\begin{array}{l}\text { P: } \quad 68,8 \%(33) \\
\text { A: } 59,1 \%(13) \\
\text { J: } 41,4 \%(29)\end{array}$ & $\begin{array}{l}\text { P: } 4,2 \%(2) \\
\text { A: } 9,1 \%(2) \\
\text { J: } 12,9 \%(9)\end{array}$ & $\begin{array}{l}\text { P: } 25,0 \%(12) \\
\text { A: } 31,8 \%(7) \\
\text { J: } 45,7 \%(32)\end{array}$ \\
\hline $\begin{array}{l}\text { Só há democracia por } \\
\text { meio da participação } \\
\text { direta do cidadão em } \\
\text { todas as decisões políticas }\end{array}$ & $\begin{array}{l}\text { P: } 66,7 \%(32) \\
\text { A: } 31,8 \%(7) \\
\text { J: } 27,1 \%(19)\end{array}$ & $\begin{array}{l}\text { P: } 2,1 \%(1) \\
\text { A: } 13,6 \%(3) \\
\text { J: } 8,6 \%(6)\end{array}$ & $\begin{array}{l}\text { P: } 29,2 \%(14) \\
\text { A: } 54,5 \%(12) \\
\text { J: } 64,3 \%(45)\end{array}$ \\
\hline
\end{tabular}

(Continua)

11 As alternativas "concorda fortemente" e "concorda" foram agregadas em concorda; "discorda fortemente" e "discorda" foram agregadas em discorda. 


\begin{tabular}{|l|l|l|l|}
\hline & Concorda & \multicolumn{1}{|c|}{$\begin{array}{c}\text { Nem } \\
\text { concorda } \\
\text { nem discorda }\end{array}$} & Discorda \\
\hline $\begin{array}{l}\text { A política é uma atividade } \\
\text { complexa que exige } \\
\text { habilidades especiais }\end{array}$ & P: $35,4 \%(17)$ & P: $6,3 \%(3)$ & P: $56,2 \%(27)$ \\
$\begin{array}{l}\text { que só alguns indivíduos } \\
\text { possuem. Portanto, } \\
\text { ela deve ser deixada às } \\
\text { lideranças políticas }\end{array}$ & A: $27,3 \%(6)$ & A: $4,5 \%(1)$ & A: $68,2 \%(15)$ \\
\hline
\end{tabular}

Fonte: NUSP

P: elite parlamentar

A: elite político-administrativa

J: elite judiciária

Como se percebe, a adesão ao voto como condição necessária da democracia é basicamente unânime. No entanto, em questões que se referem a formas institucionais que preveem uma participação política mais direta do cidadão comum, a taxa de concordância entre os respondentes cai drasticamente.

Os membros da fração parlamentar da classe dirigente paranaense tendem a ter uma visão mais participativa da democracia, ao contrário dos indivíduos vinculados às frações político-administrativa e judiciária. Novamente, só podemos especular a respeito dessa constatação. Quanto aos parlamentares, podemos supor duas explicações plausíveis. Primeiramente, o contato permanente desses indivíduos com a competição eleitoral e com as reivindicações dos eleitores tenderia a reforçar neles uma maior tolerância frente a formas mais participativas de democracia. No entanto, essa explicação parece pouco convincente se lembrarmos que são os mesmos parlamentares, a despeito de toda a sua experiência democrática, que se mostram os mais propensos a aceitar o fim da democracia nas situações hipotéticas que lhes apresentamos, especialmente nos casos de ameaça à propriedade privada e aos valores morais e religiosos da sociedade. Em segundo lugar, dependentes que são do voto e da opinião, talvez os parlamentares tenham mais receio de contrariar a hegemonia do "credo democrático" (DAHL, 1989, p. 84) que vigora nas sociedades contemporâneas. Fosse esse 
o caso, a adesão a uma forma mais participativa de democracia seria mais fruto de um cálculo racional do que de um apoio difuso a essa forma de governo.

Quanto aos membros das frações político-administrativa e judiciária, acreditamos que seria possível explicar a sua recusa de formas mais ousadas de participação política em função, sobretudo, dos princípios de recrutamento a que estão submetidos na sua vida profissional. O caso dos desembargadores é mais evidente. É plausível supor que o ingresso na magistratura pela via do concurso, a função, inerente à carreira, de julgar a partir do conhecimento técnico do Direito e a promoção baseada em critérios internos à instituição, em parte meritocráticos, gerem disposições "naturalmente" avessas ao "excesso" de democracia. No caso dos membros da fração político-administrativo, apesar do critério político de sua indicação ao cargo, há um claro predomínio de uma trajetória profissional em atividades técnicas no serviço público, o que também poderia gerar disposições arredias à participação de leigos em processos decisórios vistos como essencialmente técnicos. Vale lembrar que $50,1 \%$ dos membros desse grupo (fundamentalmente formado por secretários de Estado do primeiro governo de Roberto Requião) iniciaram sua carreira como servidor público concursado ou como diretor de empresa estatal ${ }^{12}$.

Para melhor qualificar a adesão dos membros da classe dirigente estadual à democracia, além das questões referentes à intensidade da participação política, apresentamos aos entrevistados proposições acerca de algumas políticas públicas caracterizadas por

12 Essas considerações, no entanto, tornam difícil explicar as frequências encontradas para a última questão. Ali, os parlamentares, mais "participacionistas" no que diz respeito às demais questões e submetidos à competição eleitoral, são os mais elitistas; os secretários de Estado, mais avessos ao participacionismo e marcados por uma trajetória mais burocrática, são os menos elitistas e, por fim, os desembargadores, diferentes em quase tudo quando comparados com os parlamentares, assemelham-se a eles nesse ponto. Agradecemos ao parecerista de Sociedade e Política por ter chamado a atenção dos autores para esse ponto. Novamente, acreditamos que parte da explicação dessas diferenças cabe às posições ideológicas. Quanto a esse ponto, vale observar o caráter acentuadamente de esquerda dos secretários de Estado do governo Requião (ver nota 14). 
diferentes níveis de "radicalismo" quanto ao objetivo da "inclusão social”. Os resultados podem ser vistos no quadro a seguir:

Quadro 4 - Posição frente a Políticas Públicas inclusivas ${ }^{13}$

\begin{tabular}{|c|c|c|}
\hline & Favorável & Desfavorável \\
\hline $\begin{array}{l}\text { Manutenção do atual sistema } \\
\text { universitário federal e estadual gratuitos }\end{array}$ & $\begin{array}{l}\text { P: } 87,5 \%(42) \\
\text { A: } 90,9 \%(20) \\
\text { J: } 76,1 \%(54)\end{array}$ & $\begin{array}{l}\text { P: } 12,5 \%(6) \\
\text { A: } 9,1 \%(2) \\
\text { J: } 24,0 \%(17)\end{array}$ \\
\hline Universalização da saúde pública & $\begin{array}{l}\text { P: } 93,8 \%(45) \\
\text { A: } 95,5 \%(21) \\
\text { J: } 94,4 \%(67)\end{array}$ & $\begin{array}{l}\text { P: } 6,3 \%(3) \\
\text { A: } 4,5 \%(1) \\
\text { J: } 5,6 \%(4)\end{array}$ \\
\hline $\begin{array}{l}\text { Garantia, com dinheiro público, de renda } \\
\text { mínima para todos os cidadãos }\end{array}$ & $\begin{array}{l}\text { P: } 77,1 \%(37) \\
\text { A: } 63,6 \%(14) \\
\text { J: } 47,8 \%(33)\end{array}$ & $\begin{array}{l}\text { P: } 23,0 \%(11) \\
\text { A: } 36,3 \%(8) \\
\text { J: } 52,1 \%(36)\end{array}$ \\
\hline $\begin{array}{l}\text { Cotas para negros nas universidades } \\
\text { públicas }\end{array}$ & $\begin{array}{l}\text { P: } 56,3 \%(27) \\
\text { A: } 59,1 \%(13) \\
\text { J: } 38,0 \%(27)\end{array}$ & $\begin{array}{l}\text { P: } 41,7 \%(20) \\
\text { A: } 40,9 \%(9) \\
\text { J: } 62,0 \%(44)\end{array}$ \\
\hline $\begin{array}{l}\text { Reforma agrária com base na } \\
\text { desapropriação de grandes propriedades } \\
\text { privadas, produtivas ou improdutivas }\end{array}$ & $\begin{array}{l}\text { P: } 52,1 \%(25) \\
\text { A: } 63,6 \%(14) \\
\text { J: } 37,1 \%(26)\end{array}$ & $\begin{array}{l}\text { P: } 48,0 \%(23) \\
\text { A: } 36,4 \%(8) \\
\text { J: } 62,9 \%(44)\end{array}$ \\
\hline
\end{tabular}

Fonte: NUSP

P: elite parlamentar

A: elite político-administrativa

J: elite judiciária

Os dados do quadro 4 são bastante interessantes, pois revelam de saída duas constatações imediatas. Primeiramente, a universalização da saúde pública ocupa posição análoga ao problema da adesão à democracia: em todos os setores da classe dirigente local predomina uma ampla maioria favorável a esse tipo de política. Em segundo lugar, é entre os membros da elite judiciária que encontramos uma acentuada resistência às políticas sociais supostamente mais inclusivas. Exceto no caso da política de universalização da saúde, em todas as outras os desembargadores são sempre majoritariamente contra as políticas públicas sugeridas

13 Também aqui as alternativas "concorda fortemente" e "concorda" foram agregadas em concorda e "discorda fortemente" e "discorda" foram agregadas em discorda. 
pela questão, até mesmo no que se refere à manutenção de um sistema universitário federal e estadual gratuitos. As posições dos outros dois setores da classe dirigente estadual, o parlamentar e o político-administrativo, são opostas à dos desembargadores e, vale observar, semelhantes entre si. Seus membros são sempre majoritariamente favoráveis às políticas públicas em questão e com percentuais razoavelmente próximos ${ }^{14}$.

Poderíamos mobilizar os mesmos fatores utilizados para entender as posições dos membros das três frações da classe dirigente paranaense com relação à participação política para ensaiar uma explicação para a aversão da elite judiciária às políticas públicas propostas. Um tipo de trajetória profissional marcada pelo concurso público e pelo domínio de um saber especializado tende a desenvolver disposições que só admitem políticas de inclusão que levem em consideração exclusivamente o critério do mérito ${ }^{15}$.

Mas isso não seria suficiente para entender a posição dos

14 Certamente, o predomínio de indivíduos que se declaram como de esquerda e de centroesquerda no secretariado de Requião durante o período analisado (72,7\%) explica a maior propensão dos membros da fração administrativa da classe dirigente a defenderem políticas públicas mais radicais, tradicionalmente identificados com o universo ideológico das esquerdas. Nesse sentido, se compararmos os mesmos dados para a mesma fração da classe dirigente durante o período de Jaime Lerner (1995-2002), veremos que as respostas dadas às questões da tabela 4 são bem diferentes. No entanto, ainda com relação a esse ponto, vale observar que entre os dois secretariados, de Lerner e Requião, há muita semelhança quanto às questões referentes ao caráter mais participativo da democracia (tabela 3), ambos mostrando-se majoritariamente contrários às formas mais participativas da democracia. Cf. Perissinotto, 2008, p. 68.

15 Esse tipo de explicação, porém, teria de dar conta de elites judiciárias estaduais que, apesar de submetidas às mesmas regras institucionais, comportam-se de forma bem diferente, como é o caso de algumas decisões produzidas pelo Tribunal de Justiça do Rio Grande do Sul baseadas em interpretações alternativas do direito. Nesse caso, um fator adicional a ser levado em consideração seria o tipo de ensino jurídico praticado pelas escolas regionais. No caso dos desembargadores paranaenses, é interessante observar que 77,5\% deles afirmam acreditar que o direito positivo brasileiro é suficiente para solucionar eficientemente os conflitos que se apresentam ao Tribunal de Justiça. No estado do Paraná, a Universidade Federal do Paraná, a Faculdade de Direito de Curitiba e a PUC-PR são responsáveis pela formação de $78,9 \%$ dos desembargadores. Essas escolas são, portanto, importante objeto de estudo para quem pretende analisar a natureza das decisões judiciárias e as orientações normativas dos operados do direito locais. 
membros da elite político-administrativa, que, como dissemos, são em sua maioria também oriundos do serviço público. Nesse caso, e também no caso da elite parlamentar, talvez fosse mais proveitoso lembrar que os membros dessas elites se reconhecem majoritariamente como posicionados à esquerda do espectro ideológico: $48 \%$ no caso da elite parlamentar e $72,7 \%$ no caso da elite político-administrativa. No entanto, a relação entre posição no espectro ideológico e posição em relação às políticas acima mencionadas foi significativa apenas para a alternativa "Reforma agrária com base na desapropriação de grandes propriedades privadas, produtivas ou improdutivas" (com o sig $=0,008$ em d de Somers e Gamma). De qualquer forma, seja qual for a explicação mais plausível, o interessante é que, ao menos para o caso específico que estamos analisando nesse artigo, políticas públicas mais contundentes quanto à pretensão de inclusão social teriam mais facilidade para serem aceitas nas instituições que de alguma forma estão submetidas ao controle popular (ainda que indiretamente, via voto) do que pelos corredores da Justiça.

Vale observar que, ao cruzarmos a fração da classe dirigente com as posições referentes às políticas públicas enunciadas no quadro 4, as relações foram significativas para "garantia com dinheiro público de renda mínima para todos os cidadãos", "cotas para negros nas universidades" e "Reforma agrária com base na desapropriação de grandes propriedades privadas, produtivas ou improdutivas". Para todos os casos, rodamos as medidas de associação Gamma e d de Somers (duas medidas de associação para variáveis ordinais). Ao lermos as tabelas de contingência, fica clara a direção da associação: com relação à renda mínima, $31,3 \%$ dos parlamentares e $31,8 \%$ dos membros do setor político-administrativo são totalmente favoráveis, contra apenas $21,7 \%$ dos desembargadores; no que diz respeito às cotas para negros, os percentuais de totalmente favoráveis são, respectivamente, $18,8 \%, 27,3 \%$ e $15,5 \%$ e, por fim, frente à proposta de reforma agrária $14,6 \%$ dos parlamentares e $31,8 \%$ dos membros do setor 
Classe dirigente e cultura política no estado do Paraná (2002-2006)

Renato Perissinotto • Paula Adriana Wagnitz

político-administrativo se disseram totalmente favoráveis, contra apenas $8,6 \%$ dos desembargadores.

\section{Quais são os obstáculos à consolidação da democracia}

Seja qual for o percentual de adesão ao regime democrático e a compreensão que os entrevistados demonstraram ter desse sistema político, seria interessante avaliar em que medida eles consideram estar consolidada a democracia brasileira. Para tanto, elencamos um conjunto de situações que caracterizam o presente contexto social brasileiro e perguntamos aos entrevistados se concordavam ou não em avaliar tais situações como obstáculos à consolidação da democracia no Brasil. Como se percebe pelos dados do quadro 5, os membros das três frações da classe dirigente avaliaram majoritariamente que tais situações se configuravam como obstáculos à consolidação do regime democrático no Brasil, havendo disparidade maior nos percentuais obtidos quando foram feitas referências ao radicalismo dos movimentos sociais.

Quadro 5 - Obstáculos à Democracia

\begin{tabular}{|c|c|c|}
\hline & Sim & Não \\
\hline $\begin{array}{l}\text { A ganância das elites é um obstáculo à } \\
\text { democracia? }\end{array}$ & $\begin{array}{l}\text { P: } 81,3 \%(39) \\
\text { A: } 90,9 \%(20) \\
\text { J: } 63,4 \%(45)\end{array}$ & $\begin{array}{l}\text { P: } 18,8 \%(9) \\
\text { A: } 9,1 \%(2) \\
\text { J: } 36,6 \%(26)\end{array}$ \\
\hline $\begin{array}{l}\text { A desigualdade de renda é um obstáculo à } \\
\text { democracia? }\end{array}$ & $\begin{array}{l}\text { P: } 93,8 \%(45) \\
\text { A: } 95,5 \%(21) \\
\text { J: } 91,5 \%(65)\end{array}$ & $\begin{array}{l}\text { P: } \quad 6,3 \%(3) \\
\text { A: } 4,5 \%(1) \\
\text { J: } 8,5 \%(6)\end{array}$ \\
\hline $\begin{array}{l}\text { O baixo nível educacional da população é } \\
\text { um obstáculo à democracia? }\end{array}$ & $\begin{array}{l}\text { P: } 87,5 \%(42) \\
\text { A: } 77,3 \%(17) \\
\text { J: } 91,5 \%(65)\end{array}$ & $\begin{array}{l}\text { P: } 12,5 \%(6) \\
\text { A: } 12,5 \%(6) \\
\text { J: } 8,5 \%(6)\end{array}$ \\
\hline $\begin{array}{l}\text { O desrespeito aos direitos humanos é um } \\
\text { obstáculo à democracia? }\end{array}$ & $\begin{array}{l}\text { P: } \quad 89,6 \%(43) \\
\text { A: } 77,3 \%(17) \\
\text { J: } 76,1 \%(54)\end{array}$ & $\begin{array}{l}\text { P: } 10,4 \%(5) \\
\text { A: } 22,7 \%(5) \\
\text { J: } 23,9 \%(17)\end{array}$ \\
\hline
\end{tabular}




\begin{tabular}{|c|c|c|}
\hline & Sim & Não \\
\hline $\begin{array}{l}\text { O radicalismo dos movimentos sociais/ } \\
\text { agitação social é um obstáculo à } \\
\text { democracia? }\end{array}$ & $\begin{array}{l}\text { P: } 41,7 \%(20) \\
\text { A: } 9,1 \%(2) \\
\text { J: } 64,8 \%(46)\end{array}$ & $\begin{array}{l}\text { P: } 58,3 \%(28) \\
\text { A: } 90,9 \%(20) \\
\text { J: } 35,2 \%(25)\end{array}$ \\
\hline $\begin{array}{l}\text { A corrupção nos órgãos públicos é um } \\
\text { obstáculo à democracia? }\end{array}$ & $\begin{array}{l}\text { P: } 93,8 \%(45) \\
\text { A: } 95,5 \%(21) \\
\text { J: } 93,0 \%(66)\end{array}$ & $\begin{array}{l}\text { P: } 6,3 \%(3) \\
\text { A: } 4,5 \%(1) \\
\text { J: } 7,0 \%(5)\end{array}$ \\
\hline $\begin{array}{l}\text { A violência e o crime organizado são um } \\
\text { obstáculo à democracia? }\end{array}$ & $\begin{array}{l}\text { P: } 85,4 \%(41) \\
\text { A: } 77,3 \%(17) \\
\text { J: } 84,5 \%(60)\end{array}$ & $\begin{array}{l}\text { P: } 14,6 \%(7) \\
\text { A: } 22,7 \%(5) \\
\text { J: } 15,5 \%(11)\end{array}$ \\
\hline
\end{tabular}

Fonte: NUSP

P: elite parlamentar

A: elite político-administrativa

J: elite judiciária

Utilizando essas informações, poderíamos imaginar algumas escalas em que poderíamos situar as frações da classe dirigente por nós analisadas. Os obstáculos apresentados por nós como alternativas aos respondentes poderiam ser assim divididos: obstáculos sociais (ganância das elites, desigualdade de renda e baixa escolaridade das massas); obstáculos jurídico-políticos (atentado aos direitos humanos e agitação social) e, por fim, na falta de termo melhor, obstáculos criminais (corrupção e violência).

Com relação aos obstáculos sociais, podemos dizer que os desembargadores ocupam um polo da escala, os parlamentares uma posição intermediária e os membros da elite administrativa, o outro polo. Entre os desembargadores, $36,6 \%$ avaliam que a ganância das elites não é um obstáculo à democracia, contra apenas $18,8 \%$ e 9,1\% dos membros das elites parlamentares e político-administrativas, respectivamente. Os percentuais são muito semelhantes quando se trata de avaliar a desigualdade de renda. O percentual dos que acham que a desigualdade de renda não é um obstáculo à democracia é maior entre os membros da elite judiciária do que o encontrado nos outros dois setores. Por fim, é entre os desembargadores que encontramos o menor percentual daqueles que pensam que a baixa escolaridade da população não é um obstáculo à democracia: $8,5 \%$ contra 12,5 nos outros dois setores. Ou seja, entre 
os obstáculos sociais, os desembargadores não temem a ganância das elites, mostram-se mais propensos a não ver a desigualdade de renda como um problema e a temer a baixa escolaridade da população como ameaça à democracia.

No que diz respeito aos obstáculos jurídico-políticos esse padrão se repete. É também entre os desembargadores que encontramos o maior percentual dos que consideram o "radicalismo dos movimentos sociais" como um obstáculo à democracia: $64,8 \%$ contra apenas $41,7 \%$ e $9,1 \%$ das elites parlamentares e político-administrativas, respectivamente. A propósito desta alternativa, o resultado do cruzamento foi significativo ( $p=0,000$ e coeficiente de contingência de 0,36 ) e a análise dos resíduos padronizados mostra que as relações significativas ocorrem, por um lado, entre o setor judiciário e a resposta afirmativa e, por outro, entre o setor administrativo (que, lembramos, é esmagadoramente de esquerda) e a resposta negativa. Quanto ao problema da violação dos direitos humanos, os desembargadores e os membros da elite político-administrativa encontram-se muito próximos (23,9\% e 22,7\%, respectivamente, não acreditam ser esse um obstáculo à democracia) e distantes, ambos, dos parlamentares, para os quais apenas $10,4 \%$ adotam a mesma posição. Nesse caso, embora o percentual referente à elite judiciária seja muito próximo do encontrado na elite político-administrativo, é surpreendente que seja tão alto num grupo formado por operadores do direito supostamente compromissados com o respeito à lei.

Por fim, com relação ao que chamamos de "obstáculos criminais”, o padrão encontrado anteriormente se desfaz. Para 7,0\% da elite judiciária, a corrupção nos órgãos públicos não é um obstáculo à democracia, muito próximo dos 6,3\% expressos pelos parlamentares. Esses dois setores da elite estão novamente muito próximos quanto à sua avaliação acerca da violência e do crime organizado: 15,5\% e $14,6 \%$, respectivamente, não consideram esse problema como um obstáculo à democracia. A elite administrativa expressa percentuais menores no primeiro caso $(4,5 \%)$ e maiores no segundo $(22,7 \%)$.

Mais uma vez, a explicação desses achados, sobretudo no que diz respeito aos dois primeiros tipos de obstáculos à democracia, 
não pode ser fornecida pelos dados que temos à nossa disposição. Como explicar a visão, por assim dizer, mais "conservadora" dos desembargadores, que não repudiam a ganância das elites e temem o radicalismo dos movimentos sociais? Essa maior tendência de "apego à ordem"16 talvez possa ser explicado pela própria socialização profissional ao longo da carreira judiciária, que, no caso dos desembargadores, é bastante longa ${ }^{17}$. A posição mais "progressista" da elite administrativa, a nosso ver, estaria relacionada com a posição ideológica de seus membros, pois $72,7 \%$ se situam à esquerda do espectro ideológico, contra apenas $48 \%$ dos parlamentares.

Seja qual for a explicação, mais uma vez parece plausível supor que os setores da classe dirigente, ao menos no período por nós analisado, submetidos direta ou indiretamente ao processo eleitoral tendem a ter posições marcadas por uma compreensão mais ampla de democracia do que aquela expressa pela elite judiciária, cujo processo de recrutamento é predominantemente marcado por critérios burocráticos (carreira pública), meritocráticos (posse de um saber especializado) e funcionais (desempenho na carreira).

\section{Considerações finais}

Este texto partiu do pressuposto de que orientações subjetivas de atores politicamente relevantes, responsáveis por decisões que afetam a vida de milhões de pessoas, são importantes

16 Quanto a esse ponto, vale a pena apresentar o seguinte dado: quando apresentados ao enunciado "a manutenção da ordem social pressupõe, por parte de todas as pessoas, a obediência rigorosa às hierarquias sociais", 56,5\% dos desembargadores concordaram com a afirmação, $8,7 \%$ se mostraram indiferentes e 34,8\% discordaram. Infelizmente, essa questão não foi contemplada no questionário aplicado aos outros setores da classe dirigente paranaense.

17 Os dados sobre o tempo de carreira, medido pela diferença entre o ano de ingresso no Tribunal de Justiça e o ano de ingresso na carreira de magistrado, advogado ou promotor (esses duas últimas ocupações por conta do Quinto Constitucional), revelam que a carreira mais curta contava, no ano da entrevista (2006), 17 anos; a mais longa, 41 anos e a moda, 27 anos, com $14,1 \%$ dos casos. 
na medida em que podem definir o escopo de sua ação efetiva. Desse modo, foi nosso objetivo descrever e analisar as atitudes que os membros de três frações da classe dirigente paranaense os parlamentares, os secretários de Estado e os desembargadores do Tribunal de Justiça -, entre 2002 e 2006, manifestaram com relação à adesão à democracia e às suas concepções sobre esse sistema político. A partir da análise dos dados aqui apresentados, podemos enunciar as seguintes conclusões provisórias.

Em primeiro lugar, os membros das três frações da classe dirigente paranaense expressam uma esmagadora adesão à democracia como melhor forma de governo e ao voto como o instrumento que, por excelência, caracteriza esse sistema político. Nesse caso, estamos claramente na presença de um consenso impressionante. No entanto, esse consenso avassalador se desfaz assim que outras questões relativas à democracia são apresentadas aos entrevistados.

A diferença entre as três frações da classe dirigente manifesta-se inicialmente quanto à eventual aceitação do fim do regime democrático em determinadas situações hipotéticas. Surpreendeu-nos quanto a esse ponto a maior propensão dos parlamentares a aceitarem o fim do regime democrático nas situações apresentadas, seguidos, também de maneira surpreendente, pelos autointitulados defensores do Estado de direito, que são os desembargadores. Os membros do setor político-administrativo, majoritariamente formado por indivíduos situados à esquerda do espectro ideológico, revelaram-se os mais resistentes a aceitarem o fim do sistema.

As três frações da classe dirigente paranaense se diferenciam também quanto ao tipo de democracia que têm em mente. Os setores político-administrativo e parlamentar se mostraram claramente mais favoráveis a concepções mais participativas e mais igualitárias do regime democrático do que os membros ligados à fração judiciária, representada pelos desembargadores do Tribunal de Justiça. Nesta última encontramos o maior percentual de posições contrárias a caracterizar instituições mais participativas (conselhos gestores e orçamentos participativos) como essenciais à caracterização de um regime como democrático. Nela também encontramos o maior per- 
centual de posições contrárias a políticas públicas de caráter mais radicalmente inclusivo (a reforma agrária em terras produtivas e as cotas raciais). Como dissemos anteriormente, esses dados sugerem que, no caso do Paraná durante o período analisado, as chances de que políticas similares a essas fossem encampadas pela classe dirigente local seriam maiores entre aqueles membros da classe dirigente submetidos direta ou indiretamente à competição eleitoral do que entre os membros da elite judiciária.

Essa tendência a um maior "apego à ordem" por parte dos desembargadores se expressa também no fato de entre eles encontrarmos o maior percentual dos que apontam o radicalismo dos movimentos sociais como obstáculo à democracia. Além disso, surpreendeu-nos encontrar nesse grupo, cujos indivíduos quase sempre se definem como os pilares do Estado de direito, um alto percentual de respondentes que avaliam que a ameaça aos direitos humanos não se constitui em obstáculo à democracia.

Por fim, a interpretação que fizemos desses achados sugere que a explicação de tais diferenças deve ser buscada tanto na socialização política, que explicaria as diferenças entre os membros do setor político-administrativo e os parlamentares, quanto na socialização profissional, mais ou menos burocrática, mais ou menos política. No entanto, dados mais rigorosos seriam necessários para transformar essas observações em algo mais do que especulações.

Primeira versão recebida em: 23/11/2010

Versão final recebida em: 30/11/2011

\section{Bibliografia}

ALBERTONI, Ettore A. Doutrina da classe política e teoria das elites. Rio de Janeiro, Imago, 1990.

ALMOND, Gabriel A.; VERBA, Sidney. The Civic Culture: political attitudes and democracy in five nations. USA: Sage Publications, 1989. 
VERBA, Sidney (ed.). The Civic Culture Reviseted Boston, Little, Brown and Company, 1980.

CASTRO, Lucas Fernando; POLATTI, Rafaela; WOWK, Rafael T; PERISSINOTTO, Renato Monseff. Quem são e o que pensam os Desembargadores do Tribunal de Justiça do Estado do Paraná (Banco de dados). Paraná, 2006. In: Consórcio de Informações Sociais, 2008. Disponível em: <www.cis.org.br>. Acesso em: 21 jul. 2009.

CODATO, Adriano N.; GOUVÊA, Júlio C.; PERISSINOTTO, Renato M. A elite política do Paraná, 2003-2006 (Banco de dados). Curitiba: Universidade Federal do Paraná (UFPR), 2006. Disponível em: $<$ http://www.cis.org.br>. Acesso em: 20 jun. 2010.

CZUDNOWSKI, Moshe. M. Political Recruitment. Micropolitical theory: handbook of political science. F. I. Greenstein e N. W. Polsby (eds.), vol. 2, Massachusetts, Addison-Wesley Publishing Company, 1975 : 155-242.

DAHL, Robert A. Who Governs? New Haven, Yale university Press, 1989. Paulo, 2005.

- Poliarquia. São Paulo: Editora da Universidade de São

MEISEL, James H. The Mith of the Ruling Class: Gaetano Mosca and the Elite. Michigan, Ann Arbor Paperbacks and The University of Michigan Press, 1962.

MOSCA, Gaetano. The ruling class: elementi di scienza politica. New York, Toronto, London, McGraw-Hill, 1939.

PATEMAN, Carole. Participação e teoria democrática. Rio de Janeiro, Paz e Terra, 1992.

PERISSINOTTO, Renato M. Visões de democracia nos governos Lerner e Requião ou como ainda faz sentido a distinção entre direita e esquerda. In: Estado e democracia: pluralidade de questões. Ponta Grossa, Editora UEPG, 2008.b

PERISSINOTTO, Renato M; BRAUNERT, M. B. A direita, a esquerda e 
a democracia: os valores políticos dos parlamentares paranaenses (1995-2002). Revista Opinião Pública, Campinas, v. 12, n. 1, p. 114135, 2006.

PREWITT, Kenneth. The Recruitment of Political Leaders: A Study of Citizen-Politicians. The Bobbs-Merril Company Inc., New York, 1970.

PUTNAM, Robert D. Studying Elite Political Culture: The Case of "Ideology". The American Political Science Review, v. 65, n. 3. set 1971, p. 651-681.

. Motives, Beliefs, and their Sources. In: The Comparative Study of Political Elites. New Jersey : Prentice Hall, 1976.

- Comunidade e Democracia: a experiência da Itália moderna. Rio de Janeiro: Editora Fundação Getúlio Vargas, 1996.

SCHUMPETER, Joseph A. Capitalismo, socialismo e democracia. Rio de Janeiro: Fundo de Cultura, 1961.

\section{Abstract \\ Ruling class and political culture in Paraná state (2002-2010)}

The purpose of this article is to identify the conception of democracy supported by members of three fractions from Paraná state élites: the political-administrative, the parliamentary and the judicial élites. In order to do that, we compare data obtained from the following research projects: "Paraná state judges: who are they and what do they think?" and "Who governs? Identifying political and economic élites in contemporary Paraná (2002-2006)", both conducted at Brazilian Political Sociology Research Group at Federal University of Paraná. Our main conclusion is that, despite an almost universal adherence to democracy, the three fractions have meaningful differences as regards the type of democracy they support. We finally suggest that these differences might be assigned to the kind of recruitment and political and professional socialization the members of these élites are submitted to.

Keywords: ruling class, political culture, democracy, Paraná State. 